period which includes much physical exercise and abstention from cigarette smoking. In this study only the heavy smokers failed to get back to normal in this short period though they showed the biggest percentage improvement. Earlier observation in this centre showed that, as would be expected, the heavy smokers were more likely to have begun smoking at an earlier age than lighter smokers. The impaired P.E.F. in heavy smokers and its failure to return to normal may be due to changes in the bronchial tubes dependent not only on the amount of cigarettes smoked but also on the number of years the individual had been a smoker. It is interesting that any changes at all can be detected in such young people, most of whom cannot have been smoking for many years.

The cannabis smokers, most of whom were moderate or heavy cigarette smokers, surprisingly showed initial figures as good as the non-smokers. Their percentage improvement, however, was the highest of all groups. Nevertheless, the numbers involved were too small to be of any significance.

The findings of P.E.F. in the non-smokers and light smokers on discharge agreed closely with the normal values of P.E.F. found in strictly normal subjects in this age group by Gregg and Nunn (1973).

I thank hospital officer C. S. Clark for his help in conducting this survey; Dr. Ian Gregg, director of the department of clinical epidemiology in general practice, Cardiothoracic Institute, Brompton Hospital, London, for his encouragement and advice; Dr. Michael D'Souza of the department of clinical epidemiology and social medicine, St. Thomas's Hospital Medical School, London, for the statistical analysis and his helpful criticisms; and the statistical department of the Home Office.

\section{References}

Backhouse, C. I., and James, I. P. (1969). British fournal of Addiction, 64, $75,417$.

Gregg, I., and Nunn, A. J. (1973). British Medical fournal, 3, 282

Holland, W. W., et al. (1969). Millbank Memorial Fund Quarterly, 47, 215.

\title{
Early Discharge of Infants of Low Birth Weight: A Prospective Study*
}

\author{
B. SINGER, JACK WOLFSDORF
}

British Medical fournal, 1975, 1, 362-364

\section{Summary}

A total of 495 African infants of low birth weight were discharged from Harari Maternity Hospital, Salisbury, between October 1972 and September 1973. Criteria used for discharge were (a) no clinical evidence of disease, (b) satisfactory feeding by mouth (breast or bottle or both), and (c) stable temperature control under normal room conditions. Of the 495 babies 264 fulfilled these criteria when they weighed 1801-1900 g (group 1), 99 when they weighed 1901-2000 g (group 2), and 132 (group 3) when they weighed 2001-2500 g. The overall follow-up rate of those infants living in greater Salisbury was $85.5 \%$, the health visitor playing an important contributory role in their progress, especially those in group 1.

More than two clinic visits in the first four to five weeks after discharge were essential for continuing weight gain in groups 1 and 2 but not in group 3. The mean daily weight gain for all babies at the end of four to five weeks was $26 \mathrm{~g}$.

Readmission rates for babies in groups 1,2 , and 3 were $9.5 \%, 1 \%$, and $0.8 \%$, respectively, the largest single cause for readmission being bronchopneumonia associated with hypothermia. Altogether $60 \%$ of the readmissions occurred during the two winter months (June and July). Hypothermia, associated with low environmental temperatures, played a significant part in morbidity and mortality, and twins, particularly in group 1, had a

Department of Paediatrics and Child Health, Godfrey Huggins School of Medicine, University of Rhodesia, Salisbury, Rhodesia B. SINGER, M.R.C.P., D.C.H., Consultant

JACK WOLFSDORF, DIP.PAED., F.R.C.P., Professor

mortality rate three times greater than singletons in the same group.

In general, even in underdeveloped communities singleton babies born outside the winter months with reasonable clinic or home visiting facilities can be discharged at a weight of $1800 \mathrm{~g}$ or more.

\section{Introduction}

The alarming population explosion that is still occurring in underdeveloped countries despite various attempts to limit population growth places a heavy burden on neonatal hospital beds and medical and nursing personnel. In Rhodesia the African population has increased from $4 \cdot 1$ to $5 \cdot 7$ million since 1964 (Central Statistical Office, 1973), and while $80 \%$ of the population live in rural areas many people congregate around the main cities. In Salisbury Harari Maternity Hospital is the only referral teaching maternity hospital in a $250-\mathrm{km}$ radius. Each year about 7500 referred, "prescreened," or "at risk" mothers deliver their infants in this hospital, almost half of the babies subsequently requiring management in the neonatal unit. The neonatal unit comprises 60 beds run by the department of paediatrics and includes intensive-care, transitional-care, isolation, and "well-baby" wards.

Of all the babies born in the hospital $12-17 \%$ weigh less than $2500 \mathrm{~kg}$. After recovering from their immediate postnatal problems these babies normally need to stay in hospital for feeding until an adequate discharge weight (and thus maturity) is achieved. At any time $60 \%$ of the babies in the neonatal unit fall within this category (J. Wolfsdorf and B. Singer, unpublished data). The increased mortality from infections associated with overcrowded nurseries and the costs involved in keeping patients in hospital who might be managed on an ambulatory basis prompted us to undertake a year's prospective study of babies discharged at lower than customary weights. Follow-up for the first four to five weeks after discharge was undertaken. 


\section{Patients and Methods}

From October 1972 to September 1973495 low birth weight babies were discharged from the neonatal unit when they were $(a)$ clinically well-that is, requiring no medical treatment, $(b)$ gaining weight and breast feeding adequately or on a combination of breast and bottle feeds, and (c) maintaining a thermoneutral core temperature, as measured by a rectal thermometer, without supplementary heating. Most babies fulfilled the criteria and were considered fit for discharge on reaching a weight greater than $1800 \mathrm{~g}$. Before discharge, all infants were weighed, given a course of intramuscular iron dextran $(0.5 \mathrm{ml}$ daily for three days), and where necessary mothers were instructed and given the opportunity to prepare artificial feeds. Furthermore, mothers were instructed to return to the hospital or nearest local authority clinic* should there be any anxiety about the baby before her first follow-up visit, which took place at the main hospital.

A trained African nursing sister was assigned form the local authority to act as health visitor to the babies discharged from the neonatal unit. Her duties included a weekly talk to the mothers while they cared for their babies in the unit, being in charge of the weekly well-baby follow-up clinic established for the discharged infants, and maintaining liaison with the established municipal clinics, whose sisters in the African townships could also be called upon to visit a baby in their area where necessary. She also visited the mothers and babies in their homes as often as necessary, especially if the weight gain was found to be poor at a clinic visit. A record of every sick baby requiring readmission to hospital was also kept by her and the discharge diagnosis and final outcome noted.

\section{FOLLOW-UP}

Every baby who attended the follow-up clinic was weighed and examined by one of us (B.S.). Minor illnesses and feeding problems were dealt with and treatment instituted where necessary. Seriously ill patients were immediately readmitted. Mothers with their infants were requested to attend regularly every week for four to five weeks after discharge. Mothers were encouraged to bring their babies thereafter, fortnightly and monthly, until their babies were about six months old and $/$ or weighed about $7 \mathrm{~kg}$.

Assessment of gross motor development was made at each visit and the age of head control noted. No immunizations were given, but mothers were advised to take their infants to the municipal clinic in their area at the appropriate time for immunization. (While this study was in progress the main hospital acted as the clinic. This function has since been taken over by the municipal clinics, the health visitor continuing to act as an instructor in the unit and liaison officer between the neonatal unit and municipal clinics.) Multivitamin syrup supplying 800 IU vitamin D daily was given to all infants until mixed feeding was introduced.

The infants were subdivided by discharge weight into three groups: group 1, those discharged at 1801-1900 g; group 2, those discharged at 1901-2000 g; group 3, those discharged at 2001-2500 g. The frequency of follow-up visits to the clinics during the first four to five weeks was noted, daily weight gains were computed, the reason for and number of readmissions were recorded together with the season,

*There are nine local authority clinics in greater Salisbury, all well situated in regard to the population they serve.

TABLE I-Mean Weights and Attendance Rates in Three Groups of Babies

\begin{tabular}{|c|c|c|c|}
\hline Group & $\begin{array}{l}\text { No. of } \\
\text { Babies }\end{array}$ & $\begin{array}{c}\text { Mean Weight } \\
\text { (士 S.D.) at } \\
\text { Discharge } \\
(\mathbf{g})\end{array}$ & $\begin{array}{l}\text { No. (\%) } \\
\text { Attending } \\
\text { Clinic }\end{array}$ \\
\hline $\begin{array}{c}1 \\
2 \\
3 \\
\text { Total }\end{array}$ & $\begin{array}{r}264 \\
99 \\
132 \\
495\end{array}$ & $\begin{array}{l}1838.84 \pm 29.53 \\
1959.19 \pm 26.41 \\
2152.15 \pm 100 \cdot 59\end{array}$ & $\begin{array}{l}223(83.6) \\
86(86 \cdot 9) \\
112(84 \cdot 8) \\
421(85 \cdot 1)\end{array}$ \\
\hline
\end{tabular}

and mortality rates were calculated. Statistical comparisons between the groups were made.

\section{Results}

The various groups studied and their attendance rates are shown in table I. Overall mean daily weight gains by groups and numbers of visits are recorded in table II. The babies in groups 1 and 2 failed to gain much weight if only two clinic visits were made in the first few weeks after discharge. Those babies who were seen three or more times during this period, however, gained weight satisfactorily. Babies in group 3 had a steady and satisfactory weight gain irrespective of the number of follow-up clinic visits. The $t$ values of weight increments between those who attended clinic two, three, and four times in each group are recorded in table III and indicate some significant differences $(P<0.001)$ for groups 1 and 2 . For the babies in group 3 there were no significant differences. The overall mean daily weight gain for each group after four clinic visits was $26 \mathrm{~g}$.

Morbidity and mortality are recorded in table IV. The morbidity rate was greater in group 1 than in groups 2 and 3 $(\mathrm{P}<0.001)$. The mortality rate was also greatest for group 1 $(5.6 \%)$ and significantly different from those of group 2 and 3 $(\mathrm{P}<0.01)$.

The causes and outcome of readmission are summarized in table V. The reasons for infants being at risk in group 1 are shown in table VI. Twins had a mortality rate three times greater than that of matched singletons $(5 \cdot 6 \%$ v. $15 \cdot 0 \%)$, and

TABLE III-Statistical Comparison of Weight Increments in each Group according to Numbers of Clinic Visits

\begin{tabular}{c|c|c|c}
\hline & \multicolumn{2}{|c}{$t$ Values of Weight Increments } \\
\cline { 2 - 3 } Group & 2 v. 3 Visits & 2 v. 4 Visits & 3 v. 4 Visits \\
\hline 1 & $5.3453^{*}$ & $5.0990^{*}$ & 0.4362 \\
2 & $3.9234^{*}$ & $4.1795^{*}$ & 0.0454 \\
3 & $0.9564^{2}$ & $1.6837^{2}$ & 1.0580 \\
\hline
\end{tabular}

P $\mathrm{P}<0.001$

$t$ values $>2.0$ are significant.

TABLE IV-Morbidity and Mortality in Three Groups

\begin{tabular}{c|c|c|c}
\hline Group & No. of Babies & $\begin{array}{c}\text { No. (\%) } \\
\text { Readmitted }\end{array}$ & $\begin{array}{c}\text { No. (\%) of } \\
\text { Deaths }\end{array}$ \\
\hline 1 & 264 & $25(9 \cdot 5)$ & $15(5 \cdot 7)$ \\
2 & 99 & $1(1 \cdot 0)$ & $1(1.0)$ \\
3 & 132 & $1(0 \cdot 8)$ & $1(0.8)$ \\
\hline
\end{tabular}

TABLE V-Analysis of Morbidity and Mortality Data for Three Groups

\begin{tabular}{|c|c|c|c|}
\hline Causes & $\begin{array}{l}\text { No. } \\
\text { Readmitted }\end{array}$ & $\begin{array}{l}\text { Main Months } \\
\text { of Readmission } \\
\text { (No. admitted) }\end{array}$ & $\begin{array}{c}\text { No. }(\%) \text { of } \\
\text { Deaths }\end{array}$ \\
\hline \multicolumn{4}{|c|}{ Group 1} \\
\hline \multirow{2}{*}{$\begin{array}{l}\text { Bronchopneumonia and } \\
\text { atelectasis } \\
\text { Gastroenteritis } \\
\text { Necrotizing enterocolitis } \\
\text { Budd-Chiari syndrome } \\
\text { and liver failure } \\
\text { Unknown }\end{array}$} & $\begin{array}{r}13 \\
4 \\
1\end{array}$ & $\begin{array}{l}\text { June/July (9) } \\
\text { January (3) } \\
\text { June }\end{array}$ & $\begin{array}{l}7(46 \cdot 7) \\
0 \\
1(6 \cdot 7)\end{array}$ \\
\hline & $\begin{array}{l}1 \\
6\end{array}$ & $\begin{array}{l}\text { July } \\
\text { June/July (1) }\end{array}$ & $\begin{array}{l}1(6 \cdot 7) \\
6(40 \cdot 0)\end{array}$ \\
\hline Total & 25 & June/July(15) & $15(100)$ \\
\hline Pulmonary haemorrhage & 1 Gron & May & $1(100)$ \\
\hline Gastroenteritis & 1 & October (1) & $1(100)$ \\
\hline
\end{tabular}

TABLE II-Overall Mean Daily Weight Gain in each Group according to Numbers of Clinic Visits made

\begin{tabular}{|c|c|c|c|c|c|c|c|c|c|c|c|c|}
\hline & \multicolumn{4}{|c|}{ Group 1} & \multicolumn{4}{|c|}{ Group 2} & \multicolumn{4}{|c|}{ Group 3} \\
\hline No. of visits: & 2 & 3 & 4 & Total & 2 & 3 & 4 & Total & 2 & 3 & 4 & Total \\
\hline $\begin{array}{l}\text { No. of babies } \\
\text { Mean daily weight gain (g) }\end{array}$ & $\begin{array}{c}32 \\
13.90\end{array}$ & $\begin{array}{c}80 \\
29 \cdot 17\end{array}$ & $\begin{array}{c}89 \\
28 \cdot 24\end{array}$ & $\begin{array}{l}201 \\
26 \cdot 33\end{array}$ & $\begin{array}{l}10 \\
8 \cdot 54\end{array}$ & $29 \cdot 86$ & $\begin{array}{c}32 \\
29 \cdot 68\end{array}$ & $\begin{array}{c}62 \\
26 \cdot 32\end{array}$ & $21 \cdot 73$ & $\begin{array}{c}39 \\
25 \cdot 97\end{array}$ & $\begin{array}{c}42 \\
29 \cdot 23\end{array}$ & $\begin{array}{c}94 \\
26.85\end{array}$ \\
\hline
\end{tabular}


TABLE VI-Infants at Risk: Analysis of Readmissions and Deaths in 264 Group 1 Babies

\begin{tabular}{|c|c|c|c|c|}
\hline Risk Factors & No. (\%) of Infants & No. (\%) Readmitted & No. $(\%)$ of Deaths & Comment \\
\hline $\begin{array}{l}\text { Twin } \\
\text { Discharged in June/July }\end{array}$ & $\begin{array}{l}53(20 \cdot 1) \\
33(12 \cdot 5)\end{array}$ & $\begin{array}{l}11(20 \cdot 8) \\
15(45 \cdot 5)\end{array}$ & $\begin{array}{r}7(13 \cdot 2) \\
10(30 \cdot 3)\end{array}$ & $\begin{array}{l}\text { Smaller twin neglected } \\
\text { Temperature }\left({ }^{\circ} \mathrm{C}\right) \text { June } 3.4 \text { (min.)-23.4 (max.) } \\
\text { July } 1.3 \text { (min.)-25.8 (max.) }\end{array}$ \\
\hline Hypothermia & $14(5 \cdot 3)$ & $14(100)$ & $9(64 \cdot 3)$ & Inadequate subcutaneous fat or clothing \\
\hline
\end{tabular}

cold weather, with concurrent hypothermia, was associated with a high morbidity and mortality.

\section{Discussion}

The custom of keeping newborn babies of low birth weight in hospital until they achieve the traditional $2500-\mathrm{g}$ weight usually accepted as being adequate for discharge has been questioned over the past five years (Berg et al., 1969; Bauer and Tinklepaugh, 1971; Jefferson County, 1971; Dillard and Korones, 1973). In developed countries "physiological stability and parental adequacy" are the basic requirements to be met before discharge, almost independent of discharge weight (Berg and Salisbury, 1971). Readmission rates for babies discharged in such countries at weights over $2000 \mathrm{~g}$ have been about $5 \%$, while mortality after discharge has generally been less than $1 \%$. The advantages put forward for an "early discharge" policy in the U.S.A. apply even more so to underdeveloped communities. Lengthened hospital stay gives rise to overcrowded nurseries with a concommitant, and often high, incidence of and mortality from infection, particularly gastroenteritis; the smaller the baby the greater the risk. Furthermore, the costeffectiveness of an early discharge policy may be regarded only with favour in any country, hospital costs being what they are. Though such a policy has been practised in the past in some underdeveloped areas (Roman, 1965; S. Wayburne, personal communication) no prospective data exist as to its effectiveness and safety when dealing with mothers whose educational backgrounds are minimal, financial resources limited, and home environments far from the best. In Africa, however, there is one major advantage: most mothers, particularly in non-industrialized areas, breast feed their babies, often doing so adequately even when the babies weigh as little as $1600 \mathrm{~g}$.

Our results strongly suggest that, provided reasonable clinic and/or home visit back-up is available, babies who weigh more than $1900 \mathrm{~g}$ can safely be discharged from nurseries irrespective of parental education, socioeconomic status of the family, or season. Weight gain after discharge, morbidity, and mortality in our series compared favourably with that found in nurseries in the U.S.A. (Vaughan et al., 1969; Cohen and Dancis, 1948).
Furthermore, no overall differences in these values were detected between groups 2 and 3 . As a group the overall daily weight gain of group 1 was good provided adequate follow-up facilities were available. Though morbidity and mortality rates were raised as compared with the U.S.A. $(9 \% v .5 \%$ and $6 \% v$. $2 \%$ respectively) the babies in this group were much smaller, they were born to a group of mothers at risk, and their neonatal mortality rate ( 35 per 1000 live births) was far greater than reported rates for teaching hospitals in the U.S.A. Equally, infant mortality in the area is still by no means insignificant (227 per 1000 live births-Central Statistical Office, 1973). If the discharge policy was modified so that during the winter months babies were discharged only when their weights were above $1900 \mathrm{~g}$ and twins in general were not discharged below this weight morbidity and mortality rates for all the groups, including group 1, would become acceptable, even in comparison to rates for upper socioeconomic and industrialized communities.

We thank Dr. T. Stamps, Medical Officer of Health for the city of Salisbury; Sisters Earwood, Kachidza, and Nkiwani; and the nursing staff of all the municipal clinics, without whose co-operation this study could not have been undertaken. We also thank Dr. W. Castle for statistical help and Dr. M. Webster, Secretary for Health, for permission to report the findings.

Requests for reprints should be addressed to Professor J. Wolfsdorf, Department of Paediatrics and Child Health, Harari Central Hospital, Box ST 494, Southerton, Salisbury, Rhodesia.

\section{References}

Bauer, C. H., and Tinklepaugh, W. (1971). Clinical Pediatrics, 10, 467. Berg, R. B., Salisbury, A. J., and Kahan, R. (1969). Fournal of the American Medical Association, 210, 1892.

Berg, R. B., and Salisbury, A. J. (1971). American fournal of Diseases of Childhood, 122, 414 .

Central Statistical Office. (1973). Monthly Digest of Statistics. Salisbury, Rhodesian Government Printer.

Cohen, J. J., and Dancis, J. (1948). Fournal of Pediatrics, 33, 564

Dillard, R. G. and Korones, S. B. (1973). New England fournal of Medicine, 288, 131 .

Jefferson County. (1971). Fournal of Arkansas Medical Society, 68, 168.

Roman, C. (1965). Revista Chilena de Pediatria, 36, 438.

Vaughan, V. C. (1969). In Textbook of Pediatrics, ed. W. E. Nelson, V. C. Vaughan III, and R. J. McKay, p. 22. Philadelphia, Saunders.

\section{Persistent Primary Enuresis: A Urodynamic Assessment}

\section{G. WHITESIDE, E. P. ARNOLD}

British Medical fournal, 1975, 1, 364-367

\section{Summary}

Videocystourethrography with synchronous pressure and flow-rate recordings has been carried out on 50 patients

\section{Middlesex Hospital, London W1N 8AA}

C. G. WHITESIDE, B.M., F.F.R., Consultant Radiologist

E. P. ARNOLD, M.B., F.R.C.S., Clinical Research Fellow, Department of Neurology and Urology (Now Senior Lecturer in Urology, University of Otago, Dunedin, New Zealand) referred for the investigation of persistent primary enuresis. Urodynamic studies showed nocturnal enuresis to be associated mainly with normal detrusor function and nocturnal plus diurnal enuresis mainly with abnormal detrusor function. Evidence is presented which suggests that these two distinct types of enuresis occur de novo and do not overlap. Out of 18 formerly enuretic male patients nine with abnormal detrusor function showed persistent nocturnal plus diurnal symptoms.

\section{Introduction}

The term enuresis means bed-wetting during sleep and does not 